\title{
Kunst an der Messe - die Einladung zum Sehtest
}

Susi Dennler

Korrespondenz:

Dr. med. Susi Dennler Bachmattstrasse 7

CH-6818 Oetwil am See

sdennler@freesurf.ch

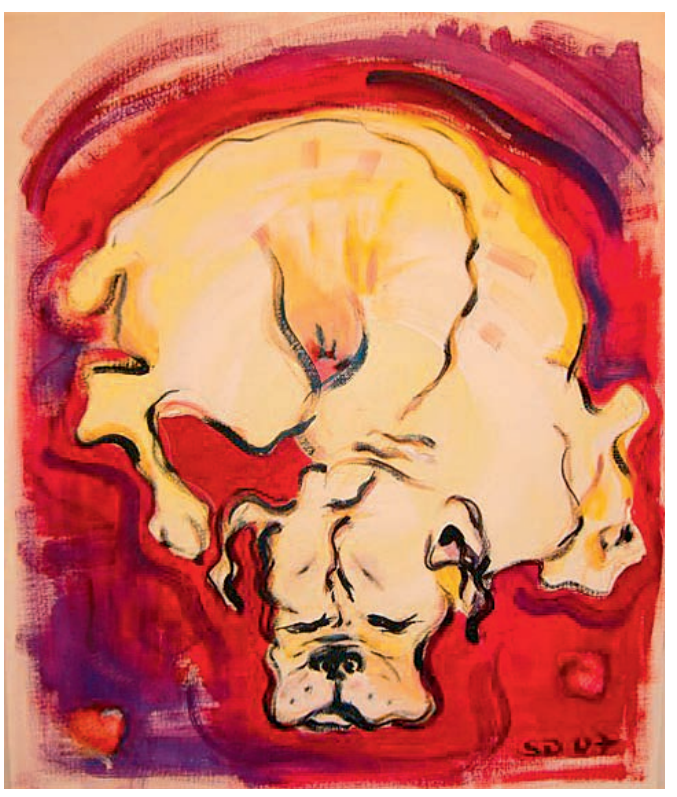

Susi Dennler: Cœur de Loup

(oder Schönheit schützt vor Falten nicht). Gouache.

Dass die Malerseele eine Mimose ist, wussten wir ja; welchen Empfindsamkeiten das zarte Organ von Malerärztinnen und -ärzten jedoch in einem Messebetrieb ausgeliefert sein kann, wurde an der ACTIVIA - der ersten Messe für Junggebliebene 50+ (na und?) - zur läuternden (und auch etwas schmerzhaften) Erfahrung. Vier Zürcher Aktive der Vereinigung «Kunstausstellung der Schweizer Ärzte, Salon des Médecins Suisses» erhielten Gelegenheit, an der ersten «Messe für Junggebliebene» vom 22. bis 25. November 2007 in der ABB-Eventhalle in Zürich-Oerlikon Bilder auszustellen. Den Organisatoren sei an dieser Stelle freundlich gedankt.

Der Kunststand im Gesundheitssektor war zentral plaziert, ein schlichter, weisser Pavillon, umgeben von Messeständen, die die Besucher professionell hartnäckig auf das Ticken der biologischen Uhr aufmerksam machten. Vis-à-vis die flotte
Demonstration eines Wackeluntersatzes für den erfolgreichen Fettstoffwechsel (bestimmte Bodyformen haben keinen, wussten Sie das schon?), nebenan die eindringliche Farbberatung für frappierendes Leugnen des Jahrgangs (wir rüsten auch Miss Fifty auf ...), dahinter Säfte und Suppen gegen den Feind Cholesterin; Magnetfelder (eine geniale Neuerfindung!) zum Draufliegen bei Rheuma, Verletzungen, Angstzuständen und ähnlichem, die Schüttelmatte für (endlich wieder) pralle Bandscheiben ... Und von sanfter Backgroundmusik umflort, wiederkehrend aufmunternde Durchsagen, jetzt oder nie Workshops und Referate zu aktuellen Lebensabschnittsproblemen zu besuchen: Mit der Leichtigkeit des Jungbleibens seien vernachlässigter Gesundheit, Erektionsschwäche und Burnout der Kampf anzusagen, sei das Fernhalten von Krankheiten als Angelegenheit von Lifestyle und Lebensart zu managen. Im Freizeitsektor dazu die muntere Aufforderung, trotz 50+ einen Sprach- oder Computerkurs zu wagen (ganz sachte), doch noch (in altersgerechter Gesellschaft) zu reisen (es gibt geeignete Hotels ohne Kindergekreisch und Jugendgelümmel), sich in Freiwilligenarbeit zu üben (man kann sie noch brauchen, die Senioren) und vor allem eines nicht zu vergessen: die längst überfällige finanzielle Vorsorge und das Testament ins

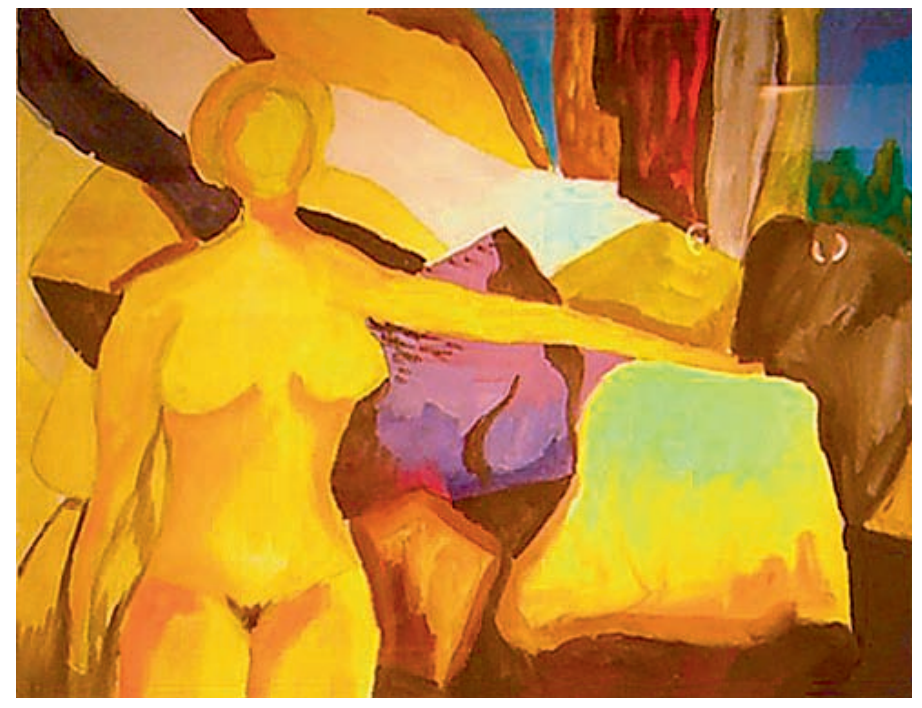

David Künzler: Akt in Steinbruch. Acryl. 
alternde Auge zu fassen. Versicherung reihte sich an Finanzinstitut, putzblanke Stände mit vornehmlich attraktiven Beraterinnen und Beratern im Weitvorfrühpensionierungsalter. Keine einzige Krankenkasse ...

Kunstsinn scheint schlecht mit geballter kommerzieller Altersproblematik und Messehektik vereinbar, so wurde die kleine verlorene
Kunstinsel der Malerärzte von der Mehrheit der Messebesucher umschifft. Wer sich jedoch in den Pavillon hineinwagte und sich mehr als ein paar Sekunden Zeit für die Bilder nahm, erhielt ansprechende Farben, Formen und Aussagen zu Gesicht, konnte sich auf die über siebzig Werke einlassen, ohne sich sehr alt zu fühlen.

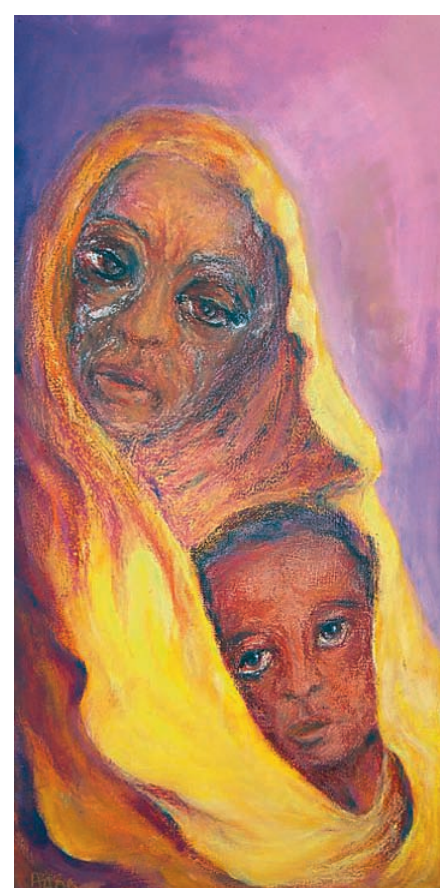

Annemarie Angst: Welche Chance? Acryl.

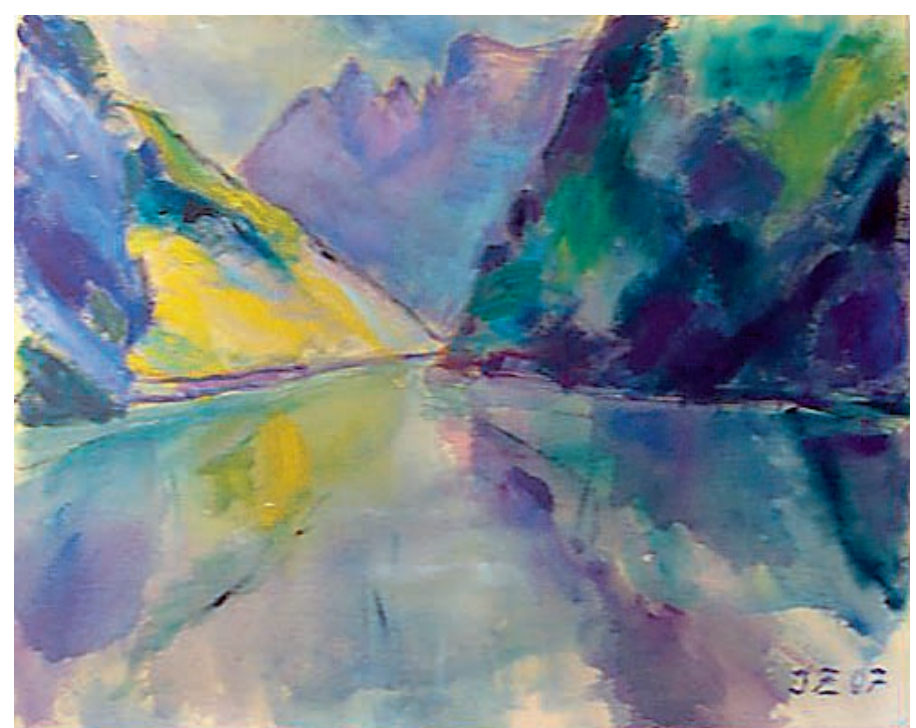

Jürg Zöbeli: Fählensee. Acryl.

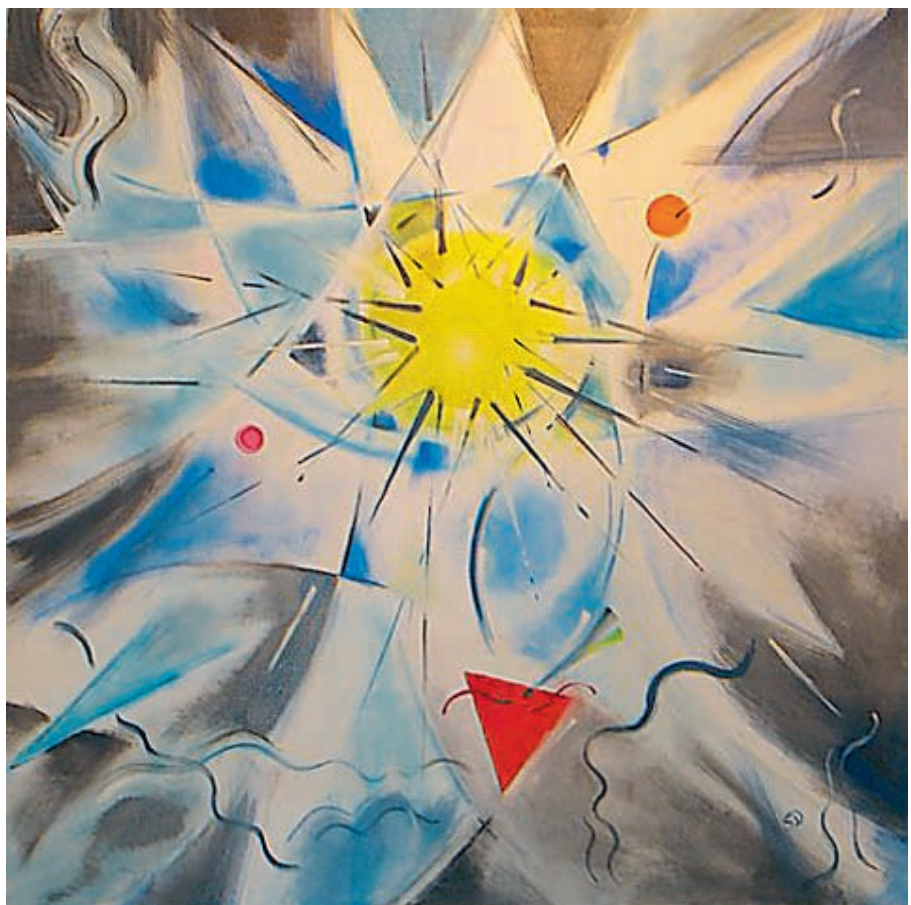

Susi Dennler: Geburt der Venus (noch eine). Öl auf Leinwand. 